\title{
COALIZÕES DE DEFESA DOS MIGRANTES INTERNACIONAIS E POLÍTICA PARTIDÁRIA, DURANTE A TRANSIÇÃO DEMOCRÁTICA, EM SÃO PAULO
}

\author{
Advocacy coalitions for international migrants and party politics \\ during the democratic transition in São Paulo
}

Patrícia Tavares de Freitas*

\begin{abstract}
Resumo. Este artigo apresenta um estudo sobre a formação e desenvolvimento de uma das coalizões de apoio e de defesa dos direitos dos migrantes internacionais na cidade de São Paulo, entre os anos 1970 e 1990. A partir da perspectiva analítica dos domínios de agência, identificamos: i) a evolução das formas de ação da coalizão ao longo do período considerado e; ii) os encaixes institucionais logrados pela coalizão durante a primeira década do período democrático, nas estruturas executivas do governo estadual.

Palavras-chave: coalizões de defesa; transição democrática; São Paulo; migrações internacionais

Abstract. This article presents a study on the formation and development of an advocacy coalition for international migrants in São Paulo, between 1970 and 1990. From the analytical perspective of the domains of agency, we identified: i) the evolution of coalition's ways of action and; ii) its institutional fits into executive spheres of state government over the first decade of the democratic period.
\end{abstract}

Keywords: advocacy coalitions; democratic transition; São Paulo State; international migrations.

Pesquisadora do Núcleo de Democracia e Ação Coletiva (NDAC), vinculado ao Centro Brasileiro de Análise e Planejamento (CEBRAP). São Paulo, SP, Brasil. 


\section{Introdução ${ }^{1}$}

Neste artigo, analisaremos alguns dos processos políticos e institucionais subjacentes às transformações contemporâneas na abordagem e localização dos migrantes internacionais, no espaço social da cidade de São Paulo: de populações isoladas, afastadas das instituições estatais e coagidas pela polícia a atores políticos relevantes no contexto local ${ }^{2}$.

Consideraremos, especificamente, os processos referentes à formação e desenvolvimentos iniciais de uma das coalizões de apoio e defesa dessas populações, entre os anos 1970 e os anos 1990. Essa coalizão é associada, no período democrático, a políticos do Partido da Social Democracia Brasileira $(\mathrm{PSDB})^{3}$. E conforma, nos dias atuais, uma das principais forças políticas em nome dos direitos dos migrantes internacionais na cidade de São Paulo, ao lado da coalizão formada em torno de políticos do Partido dos Trabalhadores (PT).

O período em foco é visto, em geral, como pouco relevante para as análises sobre a política em torno das questões migratórias no Brasil. As grandes mudanças nesse sentido começaram a ocorrer, principalmente, a partir dos anos 2000, com o estabelecimento das primeiras estruturas institucionais de apoio aos migrantes e refugiados nas capitais do país, a primeira Conferência Nacional sobre Migrações e Refúgio (Comigrar), bem como de uma série de pequenas iniciativas dos poderes públicos, municipal e estadual, direta ou indiretamente voltadas para as novas populações. E, somente em 2017, foi promulgada uma nova legislação migratória compatível, de maneira geral, com os princípios constitucionais de dignidade da pessoa humana e da inviolabilidade dos direitos fundamentais para qualquer pessoa em solo brasileiro.

Embora não tenha ocorrido nenhuma mudança paradigmática no tratamento da questão migratória no período considerado, tampouco mobilizações coletivas expressivas nesse sentido, argumentamos, neste artigo, que se trata de contexto fundamental para a organização da ação coletiva nos anos posteriores, moldando, a partir de uma série de deslocamentos, os caminhos institucionais por meio dos quais essas questões passaram a ser tratadas no governo estadual de São Paulo.

\footnotetext{
1 Neste artigo, serão expostos alguns dos resultados de uma pesquisa de pós doutorado desenvolvida no Centro de Estudos da Metrópole (CEM), entre 2014 e 2017, com financiamento da Fundação de Amparo à Pesquisa do Estado de São Paulo (FAPESP). O estudo, realizado em diálogo com os pesquisadores do NDAC, baseia-se em pesquisa documental, observação participante e em 33 entrevistas, em profundidade, com representantes da sociedade civil e dos governos municipal e estadual envolvidos com a defesa de direitos, recepção e integração dos migrantes em São Paulo.

2 Conforme argumentamos em Freitas, 2016, p. 428.

3 Na pesquisa, foram reconstituídos cinco ciclos de interação sócio-estatal (pelos direitos à educação, ao refúgio político, à saúde, à cidade e ao trabalho digno), entre os anos 1970 e 2010, e foi identificada a formação de duas coalizões de apoio: uma mais próxima dos políticos que, no período democrático, viriam a fundar o PSDB e, outra, mais próxima dos que viriam a fundar PT.
} 
O artigo parte da perspectiva analítica dos domínios de agência, desenvolvida no debate brasileiro contemporâneo sobre movimentos sociais, ação coletiva e participação política (cf. Gurza-Lavalle et alii, 2017; Gurza-Lavalle, Szwako, 2015; Gurza-Lavalle et alii, 2012). Inspirada nos pressupostos do polity approach (cf. Skocpol, 1992) e da macro sociologia histórica comparada, essa perspectiva analítica focaliza os processos de mútua constituição sócio-estatal que se desenvolvem ao longo de uma história de interações - de conflito, de aprendizagem e de cooperação - entre representantes do estado (gestores e burocratas), políticos e representantes das organizações da sociedade civil. E tem em vista, portanto, não apenas as determinantes contextuais, impulsionadoras da ação coletiva, mas seus desdobramentos e cristalizações, na medida em que a atuação das organizações civis e de suas coalizões avança ao longo do tempo.

Nesse sentido, trata-se de uma proposta analítica alternativa ao debate internacional contemporâneo sobre as determinantes institucionais da ação coletiva de migrantes ou de coalizões de defesa de seus direitos (Bloemraad, 2005; Bousetta, 2000; Koopmans, 2004; Koopmans, Stathan, 2000). Esse debate baseia-se nas teorias do processo político e, em especial, no conceito de "estruturas de oportunidades políticas" proposto pelos teóricos dos movimentos sociais (cf. McAdam, 2005; Tarrow, 2005). Esse conceito é comumente utilizado, nos desenhos de pesquisa, como variável independente, levando os autores a privilegiarem, na análise, momentos específicos ou comparações entre momentos.

Neste artigo, alternativamente, propomos flagrar a evolução interna das dinâmicas de mútua constituição sócio-estatal por meio da análise da formação e atuação de uma coalizão ${ }^{4}$. Nesse sentido, serão considerados: i) três ciclos de interação sócio-estatal em que essa coalizão adquiriu protagonismo da perspectiva da sociedade civil: em apoio aos refugiados latino-americanos, pelo direito à educação de migrantes sem documentos e pelo direito ao refúgio e, paralelamente, ii) a evolução dos encaixes institucionais logrados por essa coalizão nas estruturas do executivo estadual durante o período democrático ${ }^{5}$.

A coalizão em foco foi estabelecida em apoio aos refugiados políticos latino-americanos durante o período militar. E foi formada, principalmente, por

\footnotetext{
Conjunto de atores que atuam coordenadamente em prol de um grupo social ou uma causa (cf. Houtzager, 2003).

5 Conforme debate lançado, principalmente a partir de Scokpol (1992), e retomado contemporaneamente na proposta dos domínios de agência, os encaixes são estruturas institucionais (leis, regras, prioridades, estruturas executivas, cargos, direito de participar de conselhos, reuniões, comissões etc.) que garantem a determinados atores sociais (não a todos) algum tipo de acesso e/ou controle da atuação do estado. Ampliando, dessa forma, seletivamente, para os que lograram fazer parte dos encaixes, suas "capacidades de escolha, barganha e acordo diante do poder público e de outros atores organizados relevantes" (Gurza-Lavalle et alii, 2012, p. 187).
} 
ativistas pelos direitos humanos organizados em torno da Comissão Justiça e Paz $(\mathrm{CJP})^{6}$ e por membros da Igreja Católica, organizados em torno da Pastoral do Migrante, do Serviço Pastoral do Migrante (SPM) e da Cáritas Arquidiocesana do Estado de São Paulo.

As aberturas institucionais logradas a partir da atuação desses atores cristalizaram formas de abordagem da questão migratória em âmbito federal, com a promulgação do Estatuto do Refugiado, e encaixes institucionais no executivo do governo do estado de São Paulo, concentrados na Secretaria de Justiça e Defesa da Cidadania (SJDC).

Nas próximas duas seções, serão considerados: os momentos iniciais de formação da coalizão, durante os anos 1970 e 1980 e sua atuação no período democrático. Finalizaremos o artigo indicando algumas contribuições da perspectiva dos domínios de agência para a análise dos processos políticos considerados.

\section{Os momentos iniciais de formação de uma coalizão em defesa dos refugiados políticos latino-americanos}

A confluência entre ativistas em defesa dos direitos humanos e a questão imigratória, durante o período militar, no Brasil, nos remete à problemática do refúgio político latino-americano, principalmente, após o estabelecimento de governos militares no Chile (1973) e na Argentina (1976). Os governos autoritários recrudesceram o controle das fronteiras nacionais, refletindo a geopolítica da guerra fria na região.

No Brasil, um dos polos de resistência a esses processos de perseguição política e fechamento de fronteiras foi constituído na cidade de São Paulo, durante os anos 1970, a partir de uma parceria entre a Cáritas Arquidiocesana (que já desenvolvia um trabalho com refugiados no Rio de Janeiro), o Alto Comissariado das Nações Unidas (ACNUR) e a CJP (cf. Sprandel, Milesi, 2003, p. 123). Paralelamente, foram estabelecidas parcerias informais entre os representantes da Igreja Católica vinculados à missão scalabriniana na cidade e os ativistas da CJP, para o apoio e acolhimento dos refugiados latino-americanos na cidade 7 .

Naquele momento, a Igreja Católica passava por um período bastante progressista, consolidado no Concílio Ecumênico Vaticano II, que ocorreu sob os pontificados de João XXIII e Paulo VI, entre 1962 e 1965.

\footnotetext{
6 A CJP de São Paulo havia sido criada em 1972, a princípio, como parte da Igreja Católica. Entretanto, já em meados dos anos 1970, a CJP adquire maior autonomia, tornando-se uma organização civil. Conforme desejava dom Paulo Evaristo Arns, desde então, a CJP passa a desempenhar um novo papel, com a realização das primeiras tentativas de ações de reivindicação política na capital (cf. Iffly, 2010).

7 A missão scalabriana constitui a primeira estrutura da Igreja Católica voltada diretamente para a questão migratória no Estado de São Paulo, com um trabalho direcionado, inicialmente, exclusivamente aos italianos de primeira geração.
} 
Na América Latina, o Concílio Vaticano II foi incorporado na Segunda e na Terceira Conferência Geral do Episcopado Latino-Americano, em Medellín (1968) e Puebla (1979). É nessas circunstâncias que proliferam, por exemplo, as Pastorais Sociais, que passariam a se vincular à Conferência Nacional dos Bispos do Brasil (CNBB). Entre elas, destaca-se o estabelecimento, já em 1985, pela CNBB, do Serviço Pastoral dos Migrantes (SPM), uma pastoral social inspirada na Campanha da Fraternidade, realizada em 1980, cujo tema era "A fraternidade e os imigrantes" e o lema "Para onde vais?"8.

Nesse contexto, desde os anos 1960, em nome da "opção pelos pobres", delineada naquelas conferências episcopais, os seminaristas da missão scalabriniana iniciaram um processo de abertura de seu carisma para outros grupos de migrantes internos e internacionais na cidade de São Paulo. E passaram a atuar no processo de formação das Comunidades Eclesiais de Base, do Movimento das Organizações Voluntárias pela Promoção do Favelado (MOV) e do movimento sindical da época ${ }^{9}$.

A abertura dos seminaristas scalabrinianos aos novos contextos das migrações no país pode ser vislumbrada no estabelecimento de três instituições, entre o final dos anos 1960 e início dos anos 1970: o Centro de Estudos Migratórios (CEM), em 1969, a Associação de Voluntários pela Integração dos Migrantes $(A V I M)^{10}$, em 1974 e o Centro Pastoral dos Migrantes, em 197711. E foi justamente por meio dessas novas estruturas institucionais que se teceram as parcerias entre os missionários scalabrinianos e a CJP.

Durante as décadas posteriores, as três estruturas estabelecidas naquele momento pelos scalabrinianos - o CEM, a Casa do Migrante e o Centro Pastoral - conhecidas como Pastoral do Migrante compuseram, conjuntamente com o SPM e a Cáritas, o núcleo central de organizações civis voltadas para a defesa dos novos migrantes no pós redemocratização na cidade ${ }^{12}$.

8 Cf. <https://spmigrantes.wordpress.com/quem-somos/>.

9 De acordo com pesquisa realizada em acervo documental do CEM e entrevistas com antigos padres e funcionários da Pastoral do Migrante.

${ }^{10}$ Em meio às parcerias com a CJP, a AVIM se tornaria, em 1978, a Casa do Migrante, de acordo com o padre scalabriniano Dirceu Cutti, entrevistado pela autora.

${ }^{11}$ Conforme site oficial da missão scalabriniana, o Centro Pastoral do Migrante foi estabelecido a pedido de dom Paulo Evaristo Arns, visando justamente ao acolhimento dos refugiados latinoamericanos. Cf. <http://www.missaonspaz.org/historia > .

12 Atualmente, a Pastoral do Migrante é denominada Missão Paz, incluindo a Igreja da Paz, a Casa do Migrante e o Centro de Estudos Migratórios (CEM). Durante os anos 1980 e primeira metade dos anos 2000, essas instituições scalabrinianas e o SPM atuavam em conjunto. Tratava-se, em boa parte do período, dos mesmos padres e seminaristas que circulavam por essas estruturas institucionais. Para facilitar a fluência do texto, em todos os momentos em que a atuação dessas várias instituições ocorrer no mesmo sentido, nos referimos a essas organizações apenas como Pastoral ou Pastoral do Migrante. Essa forma de se referir a esse conjunto de instituições reproduz a forma como os próprios atores desse campo - principalmente os mais antigos - se referem a essas instituições: de maneira indiferenciada, apenas como Pastoral. 
Nesse sentido, já nos anos 1980, essas organizações atuaram de maneira central na defesa das novas populações. Nesse ano, foi publicado o Estatuto do Estrangeiro, dando impulso ao recrudescimento da fiscalização por parte da Polícia Federal, conforme foi possível perceber a partir de pesquisa no acervo de notícias do Centro de Estudos Migratórios (CEM) e das entrevistas realizadas ${ }^{13}$. Impulso que se intensificou durante o longo processo de abertura democrática e os primeiros anos da década de 1990, a despeito das incompatibilidades evidentes entre o Estatuto e a nova constituição.

Nesse período, é bastante visível o protagonismo das organizações católicas supracitadas na defesa dos migrantes. Protagonismo ancorado no prestígio conquistado pelos padres católicos durante a ditadura militar. Conforme podemos vislumbrar, por exemplo, no depoimento abaixo:

Para os migrantes, os padres são um respaldo. Eles têm espaço e têm poder. Na própria Polícia Federal, naquela época, nos anos [19]80 a coisa estava brava, por qualquer coisa você ia preso. E o Mário Miotto ${ }^{14}$ gritando e xingando os policiais lá. (...). Porque o Mario Miotto tinha uma resposta para tudo, 'manjava' muito da parte jurídica, da parte legal. Então era difícil que o policial pudesse discutir com ele. Por isso que o imigrante se apoia em um padre. Porque eles tem um lugar e são bem vistos (Depoimento de Oswaldo Augustin Ojeda ao projeto de sistematização da Memória da Pastoral). (Bomfim, 2010)

Embora o foco da atuação das instituições católicas em relação aos migrantes, em seus momentos iniciais, fosse os refugiados políticos latinoamericanos, ao longo da década de 1980, iniciava uma mudança silenciosa na composição das migrações internacionais para o país: um grupo populacional mais vulnerável do que aquele dos refugiados políticos chegava à cidade, em maiores proporções, os migrantes econômicos latino-americanos, principalmente bolivianos.

Mudança que foi sendo progressivamente percebida, durante as visitas domiciliares realizadas pelos seminaristas para a assistência aos refugiados políticos e suas famílias, conforme podemos entrever em outro depoimento transcrito em Bomfim (2010):

${ }^{13}$ Esse Estatuto, aprovado por decurso de prazo em agosto de 1980, foi elaborado a partir dos preceitos da doutrina da segurança nacional e visando à proteção do trabalhador nacional. Em linhas gerais, essa legislação passou a limitar os direitos sociais, políticos e civis dos migrantes. Seja por meio de um longo e burocrático processo de regularização, seja por meio de uma série de restrições, especialmente, aos indocumentados. E estabeleceu, como principal gestor e fiscalizador da política migratória, a Polícia Federal (PF), com o apoio do Conselho Nacional de Imigração (CNIg), vinculado ao Ministério do Trabalho.

${ }^{14}$ O Padre Mario Miotto foi indicado por dom Paulo Evaristo Arns para estabelecer o Centro de Apoio Pastoral, de acordo com pesquisa em arquivo do Centro de Estudos Migratórios. 
Eu cheguei [em São Paulo] no final de [19]88, mas comecei no começo de [19]89. Começamos com o padre Mário [Miotto]. (...) A gente começou a visitar as famílias sistematicamente. Com as fichas que existiam, ia bater nas portas, nos bairros, em toda a cidade. (...). E, no Bom Retiro, descobrimos, há muitas oficinas de costura, começamos a entrar na realidade dos bolivianos, descobrindo essa exploração do trabalho, essa vida que tinham, amontoados em uma oficina, dormindo, comendo e trabalhando. (Depoimento de Marguerita Bonassi ao projeto de sistematização da Memória da Pastoral)

Em resposta a essa nova realidade, durante os anos 1990, a Pastoral passou a desenvolver uma série de atividades com os migrantes econômicos latino-americanos que incluía, além da intermediação direta junto à PF, visitas domiciliares, assistência social e abertura da igreja para celebrações que anteriormente ocorriam no espaço privado desses migrantes ${ }^{15}$.

Na próxima seção, abordaremos os embates e articulações da coalizão em defesa dos migrantes, agora liderada pela Pastoral e pelo SPM, em suas relações com os ativistas da CJP durante essa primeira década do período democrático.

\section{A coalizão dos direitos humanos e seus encaixes institucionais durante os anos 1990}

Durante os anos 1990, as incompatibilidades entre o Estatuto do Estrangeiro e o compromisso com a defesa dos direitos humanos, inscrito na nova carta constitucional, conformaram o motor dos embates e articulações entre o poder público e a sociedade civil em torno da problemática das migrações internacionais. Abordaremos, especificamente, os acontecimentos em torno do direito ao acesso de crianças e adolescentes migrantes ao sistema estadual de ensino e do direito ao refúgio político, nacionalmente e no estado de São Paulo.

Em meio à euforia pelas conquistas da nova carta constitucional e o início de um processo de construção identitária e política dos latino-americanos na cidade, mediado pela Pastoral do Migrante e pelo SPM, uma Resolução publicada pela Secretaria de Educação do Estado de São Paulo, em janeiro de 1990, impulsionou a retomada das mobilizações e articulações em nome dos direitos dos novos migrantes.

\footnotetext{
15 “Do ponto de vista social, cultural e religioso, tem um processo também eu diria de exposição de mostrar a cultura deles. (...) Eu cheguei em São Paulo e eles faziam ainda a festa em pequenos grupos nas casas deles ou alugavam um local em que faziam a festa deles. (...) A partir dos anos 90, em 94 e 95, foi a primeira festa lá no espaço da Pastoral. (...) Então, esse é um dado interessante, a festa sai do privado e vai para o público. Público, entre aspas, porque é o público ali da Pastoral, o espaço da Pastoral. Um público controlado" (Trecho de entrevista concedida por Sidney Silva à autora).
} 
A Resolução de n. 9, publicada há poucos meses da promulgação do Estatuto da Criança e do Adolescente $(\mathrm{ECA})^{16}$, impedia que as escolas da rede aceitassem matrículas de filhos de migrantes sem documentos regularizados, devido à "responsabilidade funcional diante do Estatuto do Estrangeiro" e "a fim de evitar problemas à rede escolar estadual e aos próprios alunos" ${ }^{\prime 17}$. Essa Resolução atingia, principalmente, os novos migrantes econômicos latinoamericanos.

Embora já estivéssemos em pleno regime democrático e não se tratasse mais de apoio aos refugiados políticos latino-americanos, a coalizão de atores formada, principalmente, pela Pastoral, o SPM, a Cáritas e a CJP será reativada nesse momento.

A primeira reação das organizações católicas, após o início dos relatos de mães latino-americanas que não conseguiam mais matricular seus filhos nas escolas da rede estadual, foi a de procurar a Secretaria de Educação. Entretanto, diante da falta de informações em seu órgão administrativo, as duas entidades buscaram o diálogo com outras instituições, como "escolas, Delegacias e Coordenadorias de Ensino, a Polícia Federal, Associações para os Direitos Humanos, Consulados, Entidades para a Tutela do Menor, grupos profissionais, grupos paroquiais; ademais da divulgação nos boletins de movimentos operários, pastorais e no semanário O São Paulo, da Arquidiocese" (Bonassi, 2000, p. 176).

A falta de efetividade dessas ações iniciais e o recrudescimento da aplicação da lei que, em 1993, culminou na total impossibilidade de realizar matrículas, levaram os representantes do SPM e da Pastoral a apelar para uma estratégia própria do repertório mobilizado durante o período militar diante de violações de direitos: um pedido de mediação à Comissão de Justiça e Paz, por meio de uma conversa com dom Paulo Evaristo Arns. Diante da gravidade do assunto, além da intervenção direta de dom Paulo, foi destacado um advogado da CJP, Belisário dos Santos, para tratar pessoalmente do caso.

A primeira conquista das organizações, após o contato com a CJP, foi a realização de uma audiência com o então secretário da educação. No entanto, como se tratava de uma Resolução enviada pelo governo estadual, não podendo ser revogada pelo secretário, os avanços foram pequenos. De todo modo, para sensibilizar as autoridades federais, o secretário sugeriu a elaboração de um dossiê com informações de, pelo menos, 50 famílias que tivessem sido impedidas de matricular seus filhos (Bonassi, 2000, p. 179).

\footnotetext{
${ }^{16}$ O ECA, promulgado em julho de 1990, foi desenhado em harmonia com a nova constituição, como uma espécie de marco regulatório dos direitos humanos das crianças e adolescentes.

17 Resolução da Secretaria de Educação do Estado de São Paulo, n. 9, de 8 de janeiro de 1990 (apud Waldman, 2014, p. 208).
} 
Em fevereiro de 1994, o "Dossiê Escola" do Centro Pastoral do Migrante foi apresentado ao Ministério Público que, diante de uma Resolução estadual baseada em lei federal, decidiu não revogá-la até que a lei federal (o Estatuto do Estrangeiro) fosse modificada. Dessa forma, inicialmente, embora a questão tenha ganhado ressonância, no bojo desses processos, as articulações realizadas até o momento não haviam logrado uma resolução coletiva para o impedimento da matrícula de migrantes sem documentos.

A solução foi possível apenas graças a uma mudança no governo estadual: a eleição de Mário Covas, do PSDB, em 1995, substituindo o então governador Luiz Antônio Fleury Filho, do PMDB (Partido do Movimento Democrático Brasileiro). Após assumir o governo, Covas nomeou, para a Secretaria de Justiça, o advogado da CJP que havia atuado, nos anos anteriores, pelo direito à educação de filhos de migrantes sem documentos.

Recém empossado como Secretário de Justiça, Belisário dos Santos enviou uma representação à Secretaria de Educação que estabeleceu uma nova resolução, a Resolução n. 10, baseada na Constituição de 1988 e no ECA, que revogou a anterior e garantiu o direito à educação a todas as crianças residentes no Estado, independentemente de sua condição jurídica ${ }^{18}$.

A ação do então governador Mário Covas (sucessor de Fleury) reflete um processo mais amplo de integração da pauta dos direitos humanos nas estruturas executivas de governo, em curso tanto no nível estadual, quanto no nível federal, durante os anos 1990. Em ambos os casos, como parte importante da agenda de governo dos políticos do PSDB, eleitos para mandatos a partir de 1995: Fernando Henrique Cardoso, no âmbito federal, e Mário Covas, no estadual.

No nível estadual, um dos lócus centrais desse processo de adoção dos regimes de proteção dos direitos humanos passou ser a Secretaria de Justiça, denominada a partir de então de Secretaria da Justiça e Defesa da Cidadania (SJDC). Adicionalmente à mudança de nome, nesse governo, a secretaria passou por uma importante mudança em sua estrutura interna, a partir da publicação, em 15 de setembro de 1997, do primeiro Programa Estadual de Direitos Humanos $(\mathrm{PEDH})^{19}$.

18 "A Secretaria da Educação, considerando: - a representação da Comissão Justiça e Paz de São Paulo encaminhada pelo Secretário da Justiça e Defesa da Cidadania; - os preceitos constitucionais e o Estatuto da Criança e do Adolescente que garantem o direito de acesso a qualquer criança ou adolescente à educação, ao ensino fundamental e médio, à escola pública e gratuita (...)" (Resolução da Secretaria de Educação do Estado de São Paulo, n. 10, de 2 de fevereiro de 1995), dispõe sobre matrícula de aluno estrangeiro na rede estadual de ensino fundamental e médio (apud Waldman, 2012, p. 209-210).

${ }^{19}$ Esse plano foi formulado pelo Núcleo de Estudos da Violência (NEV) a partir das resoluções do 10 Fórum Estadual de Minorias (em que participaram representantes de 167 entidades) e de Seminários Regionais (em que participaram representantes de 294 entidades governamentais e da sociedade civil). Cf. Vieira, 1999, p. 132-135. 
Nesse PEDH, o compromisso com os migrantes internacionais foi afirmado expressamente ${ }^{20}$. Nesse sentido, foi incluído um capítulo Refugiados, migrantes estrangeiros e brasileiros, na seção III, referente aos direitos civis e políticos, ao lado de outros capítulos referentes a crianças e adolescentes, mulheres, população negra, povos indígenas, terceira idade, pessoas portadoras de deficiência e homossexuais e transexuais ${ }^{21}$.

Os migrantes, dessa forma - incluindo-se aí as categorias de refugiados e migrantes estrangeiros e brasileiros - passavam a compor, junto com outros grupos de pessoas, o rol das populações e minorias consideradas, pelo governo estadual, em circunstâncias de maior vulnerabilidade em relação à garantia de seus direitos humanos e de cidadania. Populações para as quais seria necessário o estabelecimento de estruturas e programas próprios. Nesse sentido, ao longo do tempo, os grupos arrolados no primeiro $\mathrm{PEDH}$ passaram a ser objeto de estruturas institucionais específicas no interior da SJDC.

A estrutura do PEDH assemelha-se à do Primeiro Programa Nacional de Direitos Humanos (PNDH), publicado cerca de dois anos antes, em $1996^{22}$. Trata-se do primeiro programa nacional da América Latina, tendo conformado a base programática da primeira Secretaria Nacional de Direitos Humanos, inaugurada em abril de 1997 (Pinheiro, 1999, p. 23).

No PNDH, também encontramos um capítulo específico voltado para os migrantes, intitulado "estrangeiros, refugiados e migrantes brasileiros", ao lado de capítulos referentes a outros grupos considerados vulneráveis de maneira semelhante ao $\mathrm{PEDH}^{23}$.

E foi, justamente, no interior desse processo de elaboração das diretrizes nacionais de defesa dos direitos humanos que emergem as primeiras iniciativas concretas no sentido de mudança da legislação nacional em relação aos migrantes em geral e de regulamentação do Estatuto do Refugiado, em particular. Nesse sentido, no capítulo voltado para os migrantes, são arrolados objetivos de curto, médio e longo prazo $^{24}$. Entre os objetivos citados, adquiriu centralidade, na atuação federal, pelo seu êxito, a proposta de encaminhamento

${ }^{20}$ Cf. <http://www.mpsp.mp.br/portal/page/portal/cao_civel/acoes_afirmativas/aa_doutrina/pedh. $\operatorname{pdf}>$.

${ }^{21}$ Destaca-se, no item 9.5, do capítulo referente aos migrantes, a reafirmação da necessidade de garantir a implementação da Resolução Estadual pelo direito à educação.

22 O plano foi elaborado, igualmente, a partir da participação da sociedade civil, sob coordenação de José Gregori que se tornaria o primeiro secretário nacional de direitos humanos (1997 2000). Note-se que Gregori, assim como Belisário dos Santos, também havia atuado na CJP, tendo acompanhado de perto suas ações junto aos refugiados políticos latino-americanos, durante o período militar, conforme entrevista concedida à autora.

${ }^{23}$ Da perspectiva dos grupos sociais contemplados, a única diferença entre o PNDH e o PEDH refere-se aos homossexuais e transexuais, presentes apenas no programa estadual.

${ }^{24}$ Cf. <http://www.uece.br/labvida/dmdocuments/pnhd_1.pdf $>$. 
do projeto de lei para a internalização da Convenção das Nações Unidas sobre o Estatuto dos Refugiados, elaborada no início dos anos 1950 (Barreto, 2010).

Tratava-se de uma reivindicação de várias organizações da sociedade civil e da igreja que passaram a se envolver com o tema durante a ditadura e que, durante os anos 1990, puderam participar de sua elaboração (Barreto, 2010, p. 32-33).

A lei brasileira resultante, n. 9474, sancionada em 1997, destaca-se pelo seu processo participativo e por ser bastante avançada da perspectiva da defesa dos direitos humanos dos refugiados (Barreto, 2010; Haydu, 2011). Adicionalmente, a legislação estabelece uma estrutura institucional tripartite colegiada - formada por representantes estatais, da ONU (por meio do ACNUR) e da sociedade civil - o Comitê Nacional para os Refugiados (Conare). E o Conare passa a ser responsável pela avaliação dos pedidos de refúgio e vincula-se ao Ministério da Justiça.

No âmbito estadual, a primeira estrutura institucional voltada para os direitos humanos dos migrantes internacionais é inaugurada, na SJDC, apenas em 2007, durante o governo de José Serra do PSDB, dez anos depois da publicação das diretrizes programáticas do primeiro PEDH. Trata-se do Conselho Estadual para os Refugiados $(C E R)^{25}$. Iniciativa pioneira para a promoção de políticas para refugiados no país, o CER foi, inicialmente, estabelecido como um órgão de deliberação coletiva, composto por representantes de 10 secretarias estaduais, 2 representantes de organizações não governamentais (a Cáritas e a Pastoral) e um representante da Acnur.

Apesar do pioneirismo, o CER parece não ter realizado muitas reuniões, nem ter tomado decisões relevantes no momento de sua fundação ${ }^{26}$. De todo modo, esse conselho foi reativado no final de 2011. Assumindo, desde sua reativação, um papel progressivamente mais relevante no cenário de interações sócio-estatais em torno da defesa dos direitos dos migrantes internacionais no contexto estadual ${ }^{27}$.

É interessante notar que, embora a composição do CER tenha assumido, nos anos posteriores, um formato mais plural e diversificado, até 2012 - mais de duas décadas após o estabelecimento da coalizão em foco neste artigo encontramos as duas principais organizações civis da coalizão (a Cáritas e a Pastoral) como as duas únicas organizações civis com direito a voz e voto no

\footnotetext{
${ }^{25}$ O CER foi estabelecido por meio do Decreto n. 52349, de 12 de novembro de 2007.

${ }^{26}$ Não foi encontrada nenhuma ata de reunião do CER durante os seus anos iniciais de funcionamento. A ata mais antiga encontrada, de 8 de novembro de 2011, no Diário Oficial do Estado de São Paulo, denomina-se "Ata de reunião de reativação do Comitê Estadual para Refugiados". Nesta ata são feitas menções a atuações pontuais do CER durante 2008 e 2009.

${ }^{27}$ Conforme pudemos verificar durante o trabalho de campo e a partir das entrevistas realizadas junto aos coordenadores do CER e representantes das instituições participantes.
} 
CER. E, até 2016, apesar de não serem as únicas, continuavam sendo centrais no âmbito da sociedade civil, nessa estrutura institucional estabelecida no executivo estadual.

\section{Processos de mútua constituição e encaixes institucionais na análise da ação coletiva em defesa dos migrantes}

Neste artigo, buscamos abarcar as conexões entre os processos de mútua constituição sócio-estatal de amplo alcance, em curso durante a transição democrática, e os processos de institucionalização de demandas sociais de médio alcance, expressos nos encaixes institucionais logrados pelas organizações civis em defesa dos migrantes.

De maneira geral, da perspectiva da transição democrática e primeira década dos anos 1990, são comumente indicados como fatores explicativos dos avanços na área de direitos humanos, especialmente em relação ao direito dos refugiados: i) as pressões internacionais pela plena incorporação dos regimes de proteção de direitos humanos e, ii) as pressões internas por reciprocidade de tratamento devido ao crescimento exponencial das migrações de brasileiros para o exterior nos anos 1980 (cf. Patarra, 2008; Moreira, 2010).

Neste artigo, adicionamos um terceiro fator: a história da evolução de uma coalizão cujos atores principais transitaram, durante a transição democrática, do ativismo político para a disputa partidária e, durante os anos 1990, para os governos federal e estadual. As transições resultaram no estabelecimento de uma série de encaixes em estruturas governamentais até então refratárias às questões referentes aos direitos humanos e aos migrantes internacionais. Encaixes que conectaram, para além do momento de seu estabelecimento, representantes das organizações católicas aos representantes das estruturas institucionais e executivas do governo estadual.

Nesse sentido, da perspectiva analítica dos domínios de agência aqui adotada, a nomeação de Belisário ao MJDC representa o estabelecimento do primeiro ponto de acesso institucional dos migrantes ${ }^{28}$. Posto chave na implementação dos regimes internacionais de direitos humanos no governo do Estado de São Paulo, esse ponto de acesso produz uma vinculação entre alguns dos políticos do PSDB, a causa dos migrantes e a causa da promoção dos direitos humanos das minorias, nas estruturas executivas do governo do estado de São Paulo.

De maneira geral, o ponto de acesso é transitório, posto que se sustenta na figura de uma pessoa com acesso privilegiado às estruturas estatais, cessando

\footnotetext{
${ }^{28}$ Nesse artigo, o ponto de acesso refere-se a um tipo de encaixe institucional no qual uma pessoa do movimento ou próxima a ele passa a fazer parte permanentemente ou provisoriamente de alguma estrutura político institucional do estado (Scokpol, 1992).
} 
o acesso privilegiado no momento em que a pessoa deixa de ocupar o cargo referido ou se afasta por algum motivo das organizações civis e da causa apoiada. Entretanto, ademais de informações privilegiadas e de visibilidade, o ponto de acesso pode possibilitar o estabelecimentos de novos encaixes, mais permanentes, a depender, entre outras coisas, do posto ocupado e do tipo de relação/vínculo entre o ocupante e os grupos e organizações civis a ele vinculados.

No estudo em foco, embora Belisário não fosse membro de nenhuma organização pró migrantes e refugiados, mas apenas simpatizante da causa enquanto ativista do movimento em prol dos direitos humanos, o ponto de acesso aberto com a sua entrada na SJDC não se esgota em si mesmo. Conforme vimos, logrou, inicialmente, além da revogação de uma Resolução estadual, uma nova Resolução obrigando a matrícula de crianças e adolescentes migrantes, bem como a inclusão de migrantes e refugiados no rol de populações consideradas prioritárias devido às suas condições de vulnerabilidade no PEDH que passou a reger a SJDC. Da perspectiva das organizações civis católicas que fazem parte da coalizão (Pastoral do Migrante, SPM e Cáritas) destaca-se a conquista de cadeiras no CER e sua presença quase que exclusiva nesses debates em seus momentos iniciais.

A evolução dos encaixes, por sua vez, passou a delimitar, no governo estadual, a localização e o formato das estruturas institucionais voltadas para os migrantes e refugiados no período democrático: estruturas multisetoriais e multinível na SJDC.

Na sociedade civil, permaneceram os atores católicos da coalizão que, durante o período democrático, vão estabelecer trajetória própria como principais protagonistas da proteção e da defesa de direitos dos novos migrantes internacionais em situações de vulnerabilidade na cidade de São Paulo. Durante os anos 2000, com a entrada do Partido dos Trabalhadores (PT), nos governos nacional e municipal de São Paulo, a correlação de forças começa a ser transformada, com o estabelecimento de novos atores civis (incluindo-se aí, de maneira cada vez mais visível, os coletivos dos próprios migrantes) e novas estruturas institucionais (principalmente nas estruturas do executivo municipal de São Paulo) de perfil diferenciado e que passarão, em alguns momentos, a concorrer com as estruturas do governo estadual.

A partir da abordagem dos domínios de agência consideramos ter sido possível ampliar a capacidade descritiva da análise. Permitindo identificar, a partir do mapeamento da evolução das coalizões de atores e de suas articulações e rupturas com os demais atores e estruturas da hierarquia política urbana, as formas de abordagem, conteúdos, alcances e desdobramentos potenciais da inclusão dos migrantes nos cenários político-institucionais locais. 


\section{Referências Bibliográficas}

BARRETO, Luiz Paulo. A Lei Brasileira de Refúgio: sua história. In: BARRETO, Luiz Paulo (org.). Refúgio no Brasil: a proteção brasileira aos refugiados e seu impacto nas Américas. Brasília: ACNUR, Ministério da Justiça, 2010, p. 10-21.

BLOEMRAAD, Irene. The Limits of Tocqueville: How Government Facilitates Organisational Capacity in Newcomer Communities. Journal of Ethnic and Migration Studies, v. 31, n. 5, p. 865-887, 2005.

BOMFIM, Leila Aparecida. Sistematização da Memória da Pastoral dos Imigrantes da Missão Scalabriniana Nossa Senhora da Paz. Documento do Centro de Estudos Migratórios, 2010.

BONASSI, Margherita. Canta, América sem fronteiras: imigrantes latino-americanos no Brasil. Edições Loyola: São Paulo, 2000.

BOUSETTA, Hassan. Institutional theories of immigrant ethnic mobilisation: relevance and limitations. Journal of Ethnic and Migration Studies, v. 26, n. 2, 2000, p. 229-245.

FREITAS, Patricia T. Migrações internacionais e cidadania local: um estudo sobre a formação de um novo domínio de agência na cidade de São Paulo. In: BAENINGER, Rosana et alii (org.). Imigração haitiana no Brasil. Jundiaí: Paco Editorial, 2016, p. 427-450.

GURZA-LAVALLE, Adrián; CARLOS, Euzeneia; DOWBOR, Monika; SWAKO, José. Movimentos sociais, institucionalização e domínios de agência. Série Textos para Discussão CEM. São Paulo: Centro de Estudos da Metrópole, 2017.

GURZA-LAVALLE, Adrián; SZWAKO, José. Sociedade civil, Estado e autonomia. Opinião Pública, v. 21, n. 1, p. 157-187, 2015.

GURZA-LAVALLE, Adrián; HOUTZAGER, Peter; CASTELLO, Graziela. A construção política das sociedades civis. In: GURZA-LAVALLE, Adrián (org.). O Horizonte da política: questões emergentes e agendas de pesquisa. São Paulo: Editora Unesp, Cebrap, CEM, 2012, p. 185-236.

HAYDU, Marcelo. A integração de refugiados no Brasil. In: RAMOS, André Carvalho; RODRIGUES, Gilberto; ALMEIDA, Guilherme Assis (orgs.). 60 anos de ACNUR - perspectivas de futuro. São Paulo: Editora CLA Cultural, 2011, p. 131-147.

HOUTZAGER, Peter. Coalition building from below. In: HOUTZAGER, Peter; MOORE, Mick (orgs.). Changing Paths. The new politics of inclusion in International Development. Ann Arbor: Universityof Michigan Press, 2003, p. 88-118.

IFFLY, Catherine. Transformar a metrópole: Igreja Católica, territórios e mobilizações sociais em São Paulo, 1970-2000. São Paulo: Editora da UNESP, 2010.

JUBILUT, Liliana Lyra. Migrantes, apátridas e refugiados: subsídios para o aperfeiçoamento de acesso a serviços, direitos e políticas públicas no Brasil. Série Pensando o Direito - IPEA, n. 57, 2015. 
KOOPMANS, Ruud. Migrant mobilization and political opportunities: variation among German cities and a comparison with United Kingdom and Netherlands. Journal of Ethnic and Migration Studies, v. 30, n. 3, p. 449-470, 2004.

KOOPMANS, Ruud; STATHAN, Paul. Migration, Ethnic Relations, and Xenophobia as a Field of Political Contention: an Opportunity Structure Approach. In: KOOPMANS, Ruud; STATHAN, Paul (eds.). Challenging Immigration and Ethnic Relations Politics: Comparative European Perspectives. Oxford: Oxford University Press, 2000, p. 13-56.

MOREIRA, Julia Albertino. Redemocratização e direitos humanos: a política para refugiados no Brasil. Revista Brasileira de Política Internacional, v. 53, n. 1, p. 111-129, 2010.

McADAM, Doug. Conceptual origins, current problems, future directions. In: McADAM, Doug; McCARTHY, John D.; ZALD, Mayer N. (eds.). Comparative perspectives on social movements: political opportunities, mobilizing structures, and cultural framings. Nova lorque: Cambridge University Press, 2005, p. 23-40.

PATARRA, Neide Lopes. Governabilidade das migrações internacionais e direitos humanos. Brasileiros no mundo - I Conferência sobre as Comunidades Brasileiras no Exterior. Brasília: Ministério das Relações Exteriores/Fundação Alexandre de Gusmão, v. I, 2008.

PINHEIRO, Paulo Sérgio. Brazil and the international Human Rights System. Working Paper Series, 15-00. Centre for Brazilian Studies. Universidade de Oxford, 1999. SPRANDEL, Marcia Anita; MILESI, Rosita. O acolhimento a refugiados no Brasil: histórico, dados e reflexões. In: MILESI, Rosita (org.). Refugiados - realidade e perspectivas. Brasília: CSEM/IMDH; Edições Loyola, 2003, p. 113-134.

SKOCPOL, Theda. Protecting soldiers and mothers - the political origins of social policy in the United States. MA: Harvard University Press, 1992.

TARROW, Sidney. States and opportunities: the political structuring of social movements. In: McADAM, Doug; McCARTHY, John D.; ZALD, Mayer N. (eds.). Comparative perspectives on social movements: political opportunities, mobilizing structures, and cultural framings. Nova lorque: Cambridge University Press, 2005, p. 41-61.

VIEIRA, José Carlos. Democracia e direitos humanos no Brasil (Dissertação de Mestrado). Departamento de Ciência Política do Instituto de Filosofia e Ciências Humanas, da Universidade Estadual de Campinas. Campinas, 1999.

WALDMAN, Tatiana Chang. O acesso à educação escolar de imigrantes em São Paulo: a trajetória de um direito (Dissertação de Mestrado). Faculdade de Direito da Universidade de São Paulo. São Paulo, 2012.

WALDMAN, Tatiana Chang. Migrações internacionais, movimentos sociais e acesso à justiça no Estado de São Paulo: a luta pela efetivação do direito à educação escolar. 8 Encontro da ANDHEP - Políticas públicas para a segurança pública e direitos humanos. São Paulo, 2014. 
Coalizões de defesa dos migrantes internacionais e política partidária, durante a transição democrática, em SP

Recebido para publicação em 28.01.2018

Aceito para publicação em 20.04.2018

Received for publication in January $28^{\text {th }}, 2018$

Accepted for publication in April 20 $0^{\text {th }}, 2018$

ISSN impresso 1980-8585

ISSN eletrônico 2237-9843

http://dx.doi.org/10.1590/1980-85852503880005412 